\title{
UTILIZAÇÃO DE HANSENIASPORA SP ISOLADA NO SUCO DO MELÃO NA FERMENTAÇÃO ALCÓOLICA
}

\author{
M. V. L. O. SOARES ${ }^{1}$, M. S. L. BENEVIDES ${ }^{1}$,N. C. G. $\operatorname{SILVA}^{1}$, A. D. T. \\ PINHEIRO $^{1}$ \\ ${ }^{1}$ Universidade Federal Rural do Semi- Árido, Departamento de Agrotecnologia e Ciências Sociais \\ E-mail: alvaro_eq@hotmail.com
}

\begin{abstract}
RESUMO - Hanseniasporaspé uma levedura não convencional e conhecida na literatura como composto volátil frutado capaz de melhorar o perfil sensorial de bebidas fermentadas. Esses microrganismos fermentam açucares e podem ser encontrados em frutas como o melão, que possui enorme potencial de cultivo no Rio Grande do Norte. No âmbito nacional o estado Potiguar destaca-se como maior produtor e exportador de melões amarelos. Diante disso, o presente trabalho visava avaliar a produção de etanol através da fermentação alcoólica do suco do melão amarelo utilizando a Hanseniasporasp. Para tanto, analisou-se como meio de cultura o suco de melão, suco mais o bagaço do melão e o suco juntamente com a casca do melão, onde foram colocados em uma incubadora e submetidos à temperatura de $30^{\circ} \mathrm{C}$ e uma rotação de $150 \mathrm{rpm}$ durante o período de $10 \mathrm{~h}$. Dentre os meios utilizados constatou-se o que composto contendo apenas o suco do melão obteve maior eficiência $(90,5 \%)$ na produção do etanol.
\end{abstract}

\section{INTRODUÇÃO}

De acordo com Souza (2005), o melão (Cucumis Melo L..) éconstituinte da família das curcubitáceas, pode ser consumido in natura e é considerado um fruto nobre em função de seu sabor apreciável e por possuir elevado valor nutricional na forma de hidratos de carbono, vitaminas $\mathrm{C}$, A e B1, fósforo e cálcio.

A fruticultura irrigada do Rio Grande de Norte tornou-se uma grande fonte de renda, destacando-se no âmbito nacional como o maior produtor e exportador de melões, sendo a cidade de Mossoró, localizada no Oeste Potiguar, a que tem maior potencial de cultivo de melão amarelo, afirma Souza (2005). Tal fato deve-se as favoráveis condições climáticas do Nordeste brasileiro, já que a pequena ocorrência de chuvas favorecem a baixa incidência de doenças e a melhor qualidade dos frutos.

A temperatura é um dos principais fatores climáticos que afeta a cultura do melão, pois segundo Costa (2005) à medida que a temperatura se eleva, dentro de certos limites, o fruto torna-se mais doce e a sua maturação é mais rápida e completa. Outro quesito que provoca alterações na composição do fruto é a umidade relativa, caso esteja elevada os melões produzidos serão pequenos e de sabor inferior. Quanto à umidade do ar, Brandão Filho \& Vasconcellos (1998) constataram que a mesma deve situar-se entre $65 \%$ e $75 \%$.

Assim, o melão pode ser utilizado como fonte de açucares (glicose + frutose) em fermentações alcoólicas, a qual pode ser definida como um processo anaeróbico que consiste 
na transformação de açucares em etanol e gás carbônico, podendo a mesma ocorrerà ação de leveduras, fungos e bactérias.

Segundo Kosaric (1996), os processos conduzidos por microrganismos consistem em um conjunto de operações de caracterização e o tratamento da matéria-prima, o preparo do meio de produção e propagação, a esterilização e a transformação do substrato em produto.

Dessa forma, o presente trabalho utilizou uma levedura não convencional para fermentar os açucares presentes no suco do melão, a qual pertence ao gênero Hanseniaspora. Apesar de não ser muito utilizada industrialmente, Barros (2013) afirma que tal levedura acarreta uma economia nos custos dos processos fermentativos e que é capaz de melhorar o perfil sensorial de bebidas fermentadas. Para tanto, estudou-se o processamento inicial do melão de três diferentes formas, utilizando como meio de cultura: o suco extraído da polpa do melão, da polpa +entrecasca e do fruto completo (polpa + entrecasca + casca).

\section{METODOLOGIA}

\subsection{Micro-organismo}

O microrganismo utilizado nos processos de fermentação foi a Hanseniasporasp., uma levedura isolada a partir do próprio suco do melão.

\subsection{Meios de cultura}

Para fins de manutenção, propagação e obtenção do inóculo, preparou-se uma solução de YEPD (YeastExtract-Peptone-Dextrose), ou seja, meio complexo constituído por 10 g.L $\mathrm{L}^{-1}$ de Extrato de Levedura, 20 g.L $\mathrm{L}^{-1}$ de Peptona e 30 g. $\mathrm{L}^{-1}$ de Glicose. $\mathrm{O}$ pH do meio foi ajustado para 4,5 utilizando ácido sulfúrico P.A., sendo a esterilização realizada em autoclave a $110^{\circ} \mathrm{C}$ por um período de tempo de 10 minutos.

A inoculação foi conduzida em ambiente estéril, especificamente em uma câmara de fluxo laminar, e a incubação realizada em Erlenmeyers, posteriormente colocados em um agitador orbital da marca Tecnal, modelo TE-420, sob as seguintes condições: velocidade de agitação de $150 \mathrm{rpm}$, temperatura a $30{ }^{\circ} \mathrm{C}$ por um período de $24 \mathrm{~h}$. Em seguida, o inóculo foi filtrado a vácuo na câmara de fluxo laminar para obter a concentração celular desejada para o ensaio fermentativo.

\subsection{Preparação do suco de melão}

Inicialmente, os melões foram lavados em água e álcool etílico 70\%. Em seguida, o melão foi cortado em cubos, os quais foram triturados para a obtenção do suco. Seu pH foi ajustado com ácido sulfúrico P.A. para 4,5 e sua esterilização se deu em autoclave a $110{ }^{\circ} \mathrm{C}$ por $10 \mathrm{~min}$. Avaliou-se a obtenção do suco a partir de três diferentes formas, utilizando como meio de cultura: o suco extraído da polpa do melão, da polpa +entrecasca e do fruto completo (polpa + entrecasca + casca).

\subsection{Fermentação alcoólica}

A fermentação alcoólica ocorreu em frascos de Erlenmeyer de $500 \mathrm{~mL}$, utilizando $250 \mathrm{~mL}$ de suco de melão como meio fermentativo, sendo $5 \mathrm{~g} / \mathrm{L}$ a concentração da levedura Hanseniaspora sp.. Os ensaios foram conduzidos em um agitador orbital (Tecnal - TE 420) sob agitação de $150 \mathrm{rpm}$ por 
um período de $10 \mathrm{~h}$ e a temperatura de $30{ }^{\circ} \mathrm{C}$. Amostras foram retiradas em intervalos de tempo prédefinidos para serem analisadas, sendo as alíquotas coletadas na câmara de fluxo laminar para que não houvesse contaminação.

\subsection{Métodos analíticos}

Concentração celular: Para mensurar a concentração de biomassa, fez-se uso da densidade óptica (D.O.) a $410 \mathrm{~nm}$ com auxílio de um espectrofotômetro. Esse método é baseado na medida da turvação de uma solução em função da quantidade de células em suspensão, sendo simples e rápida a sua execução.

Concentração de substrato e produto: Para mensurar as concentrações de substrato e produtos, utilizou-se cromatógrafolíquido de alta eficiência - CLAE (Waters, Milford, MA, EUA) equipado com um detector de índice de refração Waters 2414 e com uma coluna Aminex HPX-87H (Bio-Rad, Hercules, CA, EUA). Ácido Sulfúrico5 mmol. $\mathrm{L}^{-1}$ foi usado como fase móvel (eluente) na vazão de $0,5 \mathrm{~mL} \cdot \mathrm{min}^{-1} \mathrm{a} 65^{\circ} \mathrm{C}$, sendo ovolume de injeção das amostras de $20 \mu \mathrm{L}$.

Cálculo dos rendimentos e parâmetros cinéticos: A partir dos ensaios experimentais, obtiveram-se os dados necessários (concentração de biomassa, substrato, produto) para determinação dos parâmetros cinéticos da fermentação alcoólica, tais como velocidade específica de crescimento $\left(\mu_{\text {máx }}\right)$, conversão de célula em produto $\left(\mathrm{Y}_{\mathrm{p} / \mathrm{x}}\right)$, conversão de substrato em célula $\left(\mathrm{Y}_{\mathrm{x} / \mathrm{s}}\right)$, conversão, eficiência e produtividade.

\section{RESULTADOS}

Visando estudar os efeitos da fermentação alcoólica utilizando a levedura Hanseniasporasp em distintos meios de cultura (suco de melão, suco de melão + bagaço e suco de melão + casca) avaliou-se o consumo de substrato, a produção de etanol e o crescimento celular durante dez horas de fermentação como pode ser visualizado na Figura 1.

Analisando aFigura 1,percebe-se que o meio 1 contendo apenas o suco do melão apresentou resultados mais satisfatórios do que os outros meios, já que a produção de etanol (53,2 g/L) foi maior do que nos outros meios e houve estabilização no período de 8 horas de fermentação. A produção de etanol foi proporcional à quantidade de substrato em $\mathrm{g} / \mathrm{L}$ fornecido por cada meio.Outro fator que aponta o meio contendo apenas o suco de melão como o mais satisfatório é a concentração celular que apresentou valores de 15,3 g/L, estabilizando após 6 horas do início da fermentação.

Já nos outros meios observa-se que o substrato é consumido completamente após 4 horas de fermentação e a produção de etanol do suco + bagaço $(36,6 \mathrm{~g} / \mathrm{L})$ e a do suco + casca $(23,16 \mathrm{~g} / \mathrm{L})$ apresenta valores inferiores ao do meio 1 .

a) 


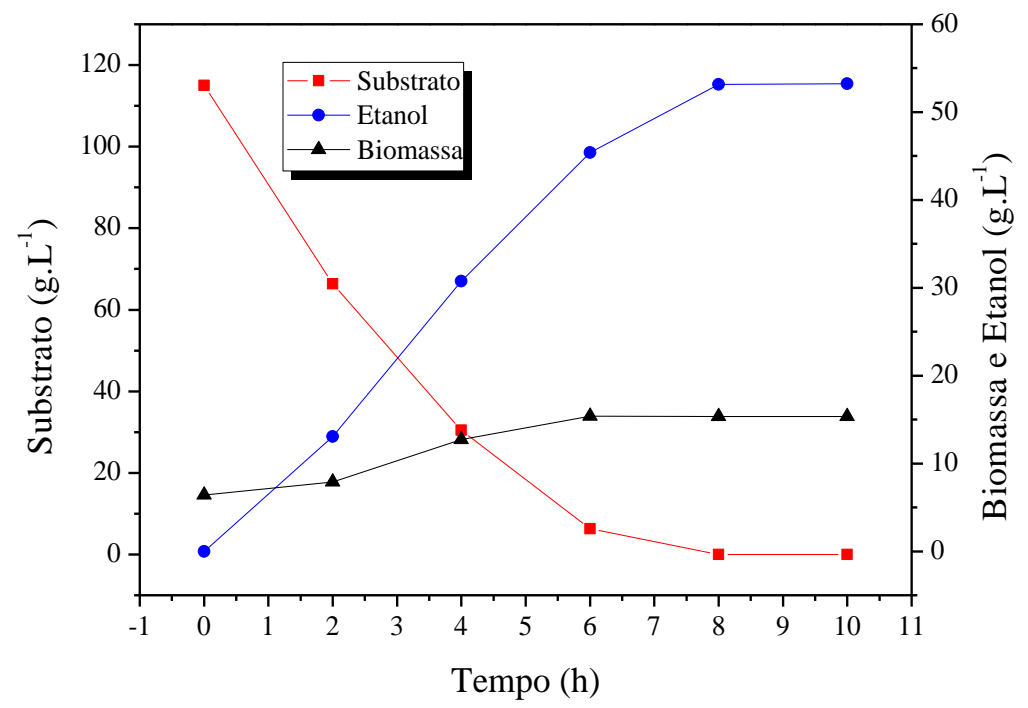

b)

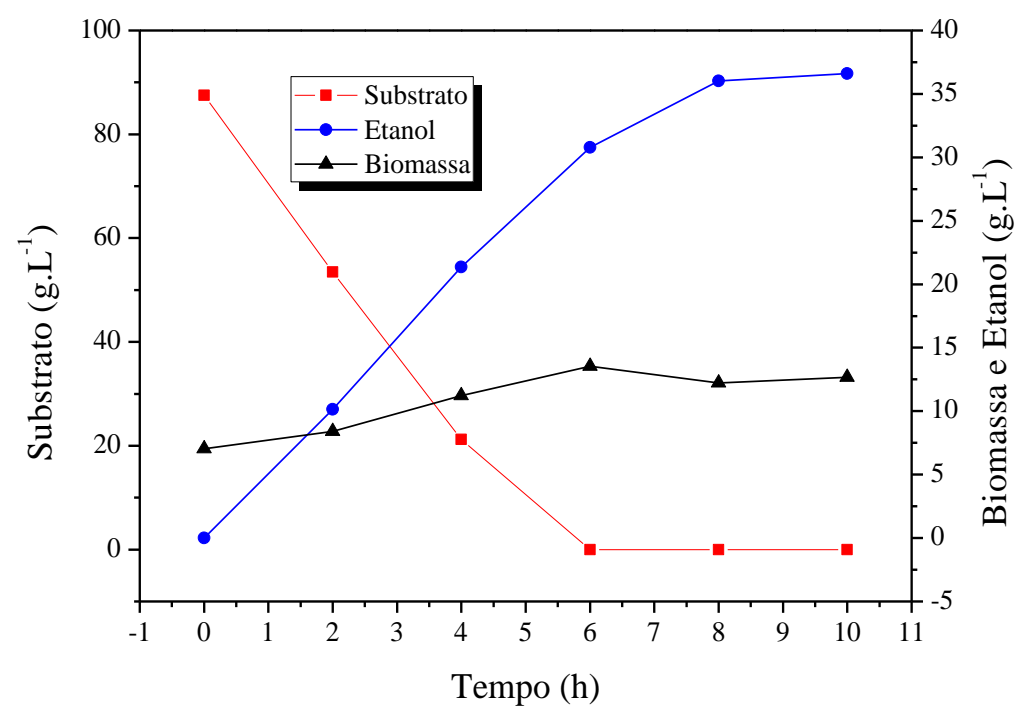

c) 


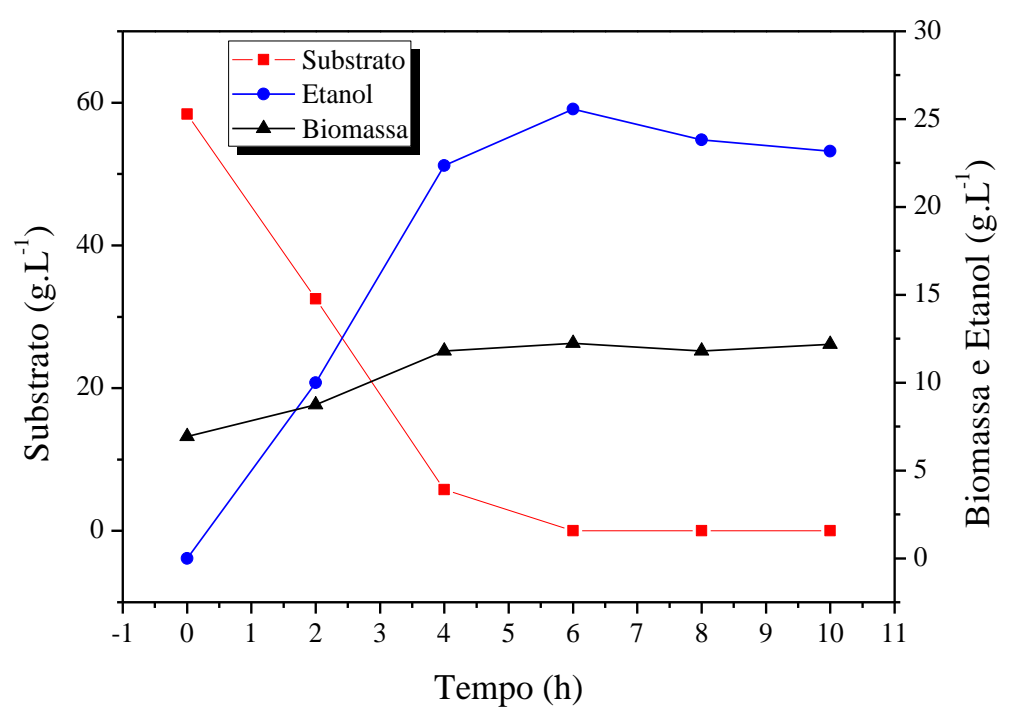

Figura 1- Efeito da suplementação do suco do melão para a produção de etanol por Hanseniasporasp a $30^{\circ} \mathrm{C}$ e $150 \mathrm{rpm}$. Onde são apresentadas respectivamente peloa) Suco b) suco + bagaço c) suco + casca

A formação de glicerol, o mais abundante dos compostos orgânicos secundários da fermentação, está acoplada à manutenção do equilíbrio redox celular, o qual é alterado quando da forma de ácidos orgânicos, biomassa e da presença de sulfito no mosto. A formação de glicerol também está relacionada a uma resposta ao estresse osmótico, quando kháconcentrações elevadas de açúcares ou de sais no mosto (LIMA et al, 2001). É importante ressaltar que em ambos os meios não ocorreu à formação de subprodutos, tais como o glicerol, o ácido acético e o metanol.

Após a fermentação dos diferentes meios de cultura, foi possível avaliar alguns parâmetros cinéticos tais como máxima velocidade especifica de crescimento $\left(\mu_{\text {máx }}\right)$, conversão de substrato em célula $\left(\mathrm{Y}_{\mathrm{x} / \mathrm{s}}\right)$, conversão de célula em produto $\left(\mathrm{Y}_{\mathrm{p} / \mathrm{x}}\right)$, conversão de substrato em produto $\left(\mathrm{Y}_{\mathrm{p} / \mathrm{s}}\right)$, eficiência $(\eta)$ e a produtividade $\mathrm{Q}_{\mathrm{P}}$ e podem ser encontrados na Tabela 1.

Verificando a Tabela 1 observa-se que a maior velocidade específica de crescimento celular $\left(0,172 \mathrm{~h}^{-1}\right)$, a conversão de substrato em produto $(0,462707)$, a produtividade $(7,563131)$ e eficiência $(90,54927)$ foi obtida utilizando o meio 1 , que é formado apenas pelo suco de melão. Provavelmente ocorreu esse maior crescimento e produção de etanol pelo fato do suco do melão apresentar uma composição mais rica de nutrientes como, vitaminas, metais e aminoácidos. 
Tabela 1 - Parâmetros cinéticosobtidos pela levedura Hanseniasporaspna fermentação do suco do melão em distintos meios de cultura a uma temperatura de $34^{\circ} \mathrm{C}$

\begin{tabular}{cccc}
\hline \multirow{2}{*}{ Parâmetros Cinéticos } & \multicolumn{3}{c}{ Meios de Cultura } \\
\cline { 2 - 4 } & Suco & Suco + Bagaço & Suco + Casca \\
\hline$\mu_{\text {máx }}\left(\mathrm{h}^{-1}\right)$ & 0,172 & 0,117 & 0,133 \\
$\mathrm{Y}_{\mathrm{X} / \mathrm{S}}(\mathrm{g} / \mathrm{g})$ & 0,077953 & 0,064399 & 0,089789 \\
$\mathrm{Y}_{\mathrm{P} / \mathrm{X}}(\mathrm{g} / \mathrm{g})$ & 5,935687 & 6,49576 & 4,420086 \\
$\mathrm{Y}_{\mathrm{P} / \mathrm{S}}(\mathrm{g} / \mathrm{g})$ & 0,462707 & 0,418321 & 0,396876 \\
$\eta(\%)$ & 90,54927 & 81,86314 & 77,66661 \\
$\mathrm{Q}_{\mathrm{P}}(\mathrm{g} / \mathrm{L} \cdot \mathrm{h})$ & 7,563131 & 0 & 4,260722 \\
\hline
\end{tabular}

Como se pode observar o suco + casca apresentou o menor rendimento de células em produto. Esse fato mostra que as células utilizam mais substrato para seu sustento do que para a produção de etanol, diminuindo assim a sua viabilidade. No entanto o meio composto pelo suco + o bagaço apresentou melhor conversão células em produto. Já a conversão de substrato em células foi maior no meio contendo o suco + casca $(0,089)$, seguindo pelo suco $(0,077)$ e com um menor valor o suco + bagaço $(0,064)$.

Em relação à quantidade de etanol produzido, percebe-se a disparidade dos resultados obtidos em ambos os meios. O suco com maior valor $\left(7,56 \mathrm{~g} \cdot \mathrm{L}^{-1} \cdot \mathrm{h}^{-1}\right)$, seguido do suco + casca $\left(4,26 \mathrm{~g} \cdot \mathrm{L}^{-1} \cdot \mathrm{h}^{-1}\right)$ e o suco + bagaço com produtividade nula.

\section{CONCLUSÃO}

A levedura isolada do suco do melão amarelo e pertencente ao gênero Hanseniasporaspfoi capaz de produzir etanol através da fermentação alcoólica com uma temperatura de $34^{\circ} \mathrm{C}$ e um $\mathrm{pH}$ ajustado para 4,5, possibilitando assim um melhor controle de infecção e redução de contaminação.Comparando os resultados entre os meios estudados, percebe-se que o meio que compreende apenas o suco de melão foi o mais satisfatório, destacando-se com 90,5\% de eficiência na produção de etanol, maior velocidade no crescimento celular e ausência na formação de subprodutos, tais como o glicerol, o ácido acético e o metanol nas análises das amostras fermentadas. Portanto, é possível obter ótimo perfil de fermentação utilizando uma levedura não convencional.

\section{REFERÊNCIAS}

BARROS, E. M. Isolamento e identificação de uma levedura obtida do suco de caju para a produção de etanol - Fortaleza, 2013.

BRANDÃO FILHO, J. U. T.; VASCONCELLOS, M.A.S. A cultura do meloeiro. In:

GOTO, R.; TIVELLI, S.W. eds. Produção de hortaliças em ambiente protegido: condições subtropicais. São `Paulo: Fundação Editora da UNESP, 1998. P.161-193. 
COSTA, N. D. O cultivo do melão. 2005-2007

KOSARIC, N.J., REED, G., PUHLER, A. E STADLER, P. Products Etanol - Potential souce of energy and chemical products. In: Rehm, H. of primary metabolism Biotechonology. 2 ed., Vch, p. 121-203, (1996).

LIMA, U. A., BASSO, L. C., AMORIM, H. V. Produção de Etanol. In: SCHMIDELL, W.; LIMA, U. A.; AQUARONE, E.; BORZANI, W. (Coord.). Biotecnologia Industrial: Processos Fermentativos e Enzimáticos, v.3, capítulo 1, São Paulo, SP, Editora Edgard Blucher, 2001.

SOUZA, F. C. S. Potencialidades e (in)sustentabilidade no semiárido potiguar. Natal: Editora do CEFET-RN, 2005. 